Journal for ImmunoTherapy of Cancer

\title{
Not all hematopoietic growth factors are created equal: should we gain information for their use with immunotherapy?
}

\author{
Paolo Bossi, ${ }^{1}$ Cristina Gurizzan, ${ }^{1}$ Luigi Lorini, ${ }^{1}$ Pierluigi di Mauro (D),${ }^{1}$ \\ Chiara Sardini, ${ }^{1}$ Marco Merlano ${ }^{2}$
}

To cite: Bossi P, Gurizzan C, Lorini L, et al. Not all hematopoietic growth factors are created equal: should we gain information for their use with immunotherapy? Journal for ImmunoTherapy of Cancer 2021;9:e003154. doi:10.1136/ jitc-2021-003154

Accepted 04 August 2021
Check for updates

(C) Author(s) (or their employer(s)) 2021. Re-use permitted under CC BY-NC. No commercial re-use. See rights and permissions. Published by BMJ.

${ }^{1}$ Department of Medical and Surgical Specialties, Radiological Sciences and Public Health, Università degli Studi di Brescia, Brescia, Italy

${ }^{2}$ Experimental Cell Therapy Lab, Medical Oncology Department, Candiolo Cancer Institute, FPOIRCCS, Candiolo, Italy

Correspondence to

Dr Paolo Bossi;

paolo.bossi@unibs.it

\begin{abstract}
Myeloid growth factors, either granulocyte colonystimulating factor (CSF) or granulocyte-macrophage CSF, are widely used to reduce the incidence and severity of chemotherapy-induced neutropenia by prophylactic or therapeutic administration. However, their activity in the novel therapeutic regimens, which often rely on the association between immunotherapy and chemotherapy, has not been thoroughly characterized yet. This paper presents some of the preclinical and clinical research regarding the putative interplay between myeloid growth factors and the immune system, advocating further studies to elucidate their potential positive or negative consequences on the outcomes when administered with immunotherapeutic agents.
\end{abstract}

\section{INTRODUCTION}

The use of granulocyte colony-stimulating factor (G-CSF) or granulocyte-macrophage CSF (GM-CSF) for prevention and treatment of neutropenia induced by chemotherapy is stated by several international guidelines. Nevertheless, limited data exist regarding their activity and their positive or negative influence on the outcomes when administered with immunotherapy plus chemotherapy.

Combination of immunotherapy using immune-checkpoint inhibitors (ICIs) and chemotherapy is widely employed to improve response rate and overcome primary resistance to immunotherapy alone: this strategy has shown increased effectiveness, at the price of higher toxicity. In particular, grade $\geq 3$ neutropenia rate varies from $10 \%$ to $22 \%$ in clinical trials, while febrile neutropenia $(\mathrm{FN})$ rate varies from $1.9 \%$ to $6.2 \%$, depending on the type of chemoimmunotherapy association (table 1). However, when ICIs are administered without chemotherapy, $\mathrm{FN}$ is very uncommon, affecting only about $0.45 \%$ of patients. ${ }^{1}$ While the administration of myeloid growth factors is essential to avoid severe consequences of $\mathrm{FN}$ and to maintain dose intensity, it is still not clear whether their use could potentially augment or impair immunotherapy efficacy.

\section{G-CSF AND CANCER}

Several solid tumors may express G-CSF or its receptor: it is hypothesized that the activation of this pathway may accelerate tumor proliferation and progression, thus making G-CSF-positive cancers more clinically aggressive and often diagnosed in advanced stages. The mechanisms mostly related to G-CSFmediated tumor progression are thought to be induction of immune tolerance and angiogenesis. $^{2}$

From a preclinical point of view, there is evidence that G-CSF induces circulating endothelial progenitor cells (EPCs) and myeloid-derived suppressor cells (MDSCs) recruitment in murine models of melanoma and lung cancer. ${ }^{2}$ While EPCs are likely important in enhancing tumor angiogenesis, MDSCs have a crucial role in inducing immune tolerance and promoting angiogenesis through the production of specific factors. A previous study suggested that G-CSF, but not GM-CSF, expression increased the number of MDSCs and induced refractoriness to antivascular endothelial growth factor therapy. ${ }^{3} \mathrm{~A}$ G-CSF-dependent tumor regrowth following therapy with vascular disrupting agents in mice has also been demonstrated. ${ }^{2}$ Moreover, it has been proposed that the signal transduction pathway activated by G-CSF may contribute to epithelial to mesenchymal transition, a critical event for the acquisition of metastatic spread, and to maintenance of a pool of cancer stem cells. ${ }^{2}$

Clinical data suggest that secretion of G-CSF could occur in different malignancies, especially in non-small cell lung cancer: at time of diagnosis, elevated G-CSF levels are associated with paraneoplastic leucocytosis, advanced disease, and have been proposed 
Table 1 FN rates in the main trials of association between chemotherapy and immunotherapy

\begin{tabular}{|c|c|c|c|c|c|}
\hline Trial & Cancer type & Drugs & $\begin{array}{l}\text { FN: chemotherapy +immunotherapy } \\
\text { arm }\end{array}$ & $\begin{array}{l}\text { FN: chemotherapy } \\
\text { arm }\end{array}$ & $\begin{array}{l}\text { G-CSF or GM- } \\
\text { CSF use }\end{array}$ \\
\hline KEYNOTE-407 & NSCLC squamous & $\begin{array}{l}\text { Pembrolizumab+carboplatin+(nab)- } \\
\text { paclitaxel }\end{array}$ & $5.4 \%$ & $3.6 \%$ & $\begin{array}{l}\text { Permitted as for } \\
\text { guidelines }\end{array}$ \\
\hline IMpower133 & SCLC & Atezolizumab+carboplatin+etoposide & $2.5 \%$ & $4.4 \%$ & NA \\
\hline KEYNOTE-048 & HNSCC & $\begin{array}{l}\text { Pembrolizumab+cis- or carboplatin }+5 \text { - } \\
\text { fluorouracil }\end{array}$ & $6.2 \%$ & $5.2 \%$ & $\begin{array}{l}\text { Permitted as for } \\
\text { guidelines }\end{array}$ \\
\hline IMpassion130 & Breast cancer & Atezolizumab+nab-paclitaxel & $1.9 \%$ & $2.2 \%$ & NA \\
\hline
\end{tabular}

FN, febrile neutropenia; G-CSF, granulocyte colony-stimulating factor; GM-CSF, granulocyte-macrophage colony-stimulating factor; HNSCC, head and neck squamous cell carcinoma; NA, not available; NSCLC, non-small cell lung cancer; SCLC, small cell lung cancer.

as a negative prognostic biomarker. ${ }^{4}$ Autocrine and/or paracrine growth stimulation via G-CSF has also been described in other neoplasms, such as melanoma and bladder cancer, and cases of rapid progressive tumors have been reported in the literature. ${ }^{25}$

\section{DUAL ROLE OF GM-CSF IN CANCER}

GM-CSF is a glycoprotein whose activity is primarily inflammatory, due to its role as a growth and differentiation factor for granulocytes, macrophage populations, and dendritic cells (DCs), which are antigen-presenting cells involved in primary and secondary T-cell immune responses, particularly against tumors. ${ }^{6}$

The effects of GM-CSF seem to be dose-dependent and context-dependent: at lower doses GM-CSF could modulate the DCs into a 'tolerogenic phenotype' involved in regulatory $\mathrm{T}$ cells (Treg) homeostasis, leading to hyporesponsivity or anergy of effector T cells; in contrast, higher doses of GM-CSF could promote myeloid proliferation, macrophages activation and angiogenesis inhibition, leading to an increased immune response. ${ }^{7}$ However, the window of activity in terms of immunostimulation should be balanced, as supratherapeutic dose of GM-CSF might favor immune evasion strategies by differentiating precursors cells into myeloid suppressor ones. ${ }^{6-8}$

Preclinical studies showed that modified melanoma cells, engineered to express GM-CSF, lead to a greater tumor immune response when treated with radiotherapy. ${ }^{8}$

Moreover, it has been shown that the combination of PD-1 blockade with GM-CSF secretion could improve antitumor response by the upregulation of several Th1 cytokines, including interferon- $\gamma$, tumor necrosis factor- $\alpha$, interleukin (IL)-2 and IL-12, which are chemoattractant for neutrophils, monocytes, and lymphocytes, releasing the state of immunosuppressive microenvironment and augmenting the tumor-reactive T-cell response. ${ }^{9}$

Clinical response greater than $50 \%$ for hormonerefractory prostate cancer combining systemic GM-CSF with ipilimumab, an ICI that blocks Cytotoxic T-Lymphocyte Antigen 4 (CTLA-4), was initially demonstrated; subsequently, in a phase III clinical trial intratumoral administration of talimogene laherparepvec, containing the gene coding for human GM-CSF, enhanced antitumoral immune response, thus leading to increased efficacy in comparison to administration of subcutaneous GM-CSF. $^{10}$

Other initial clinical experiences raised the possibility of important therapeutic interactions between immunotherapy and GM-CSF. A clinical benefit has been observed in melanoma using the combination of an ICI and sargramostim, a recombinant GM-CSF, possibly due to improved antigen presentation via recruitment of DCs and macrophages. ${ }^{7}$ Moreover, patients treated with sargramostim and ICI reported less severe adverse events compared with ICI alone.

Finally, GM-CSF showed to induce an increased immune response when administered concomitantly with radiation therapy, presumably by boosting the DCs differentiation.

Therefore, GM-CSF activity seems to be depending on dose, presence or absence of other relevant cytokines, and on additional factors in the tumor microenvironment, such as CTLA-4 expression and degree of inflammation; it would be interesting to determine whether GM-CSF promotes antitumor immune responses or tumor spread, but it also seems quite clear that it plays a key role in modulating immune response.

\section{CONCLUSION}

Preclinical studies have showed a theoretical negative interaction between G-CSF and the immune system. Even if reliable and convincing clinical data to support this hypothesis lack, more caution should be put in administering myeloid growth factors in the context of immunotherapy.

On the other hand, GM-CSF could have a favorable impact when added to immunotherapy with ICIs, both in terms of modulating immune response and reducing severe adverse events, thus potentially increasing effectiveness. Its role, however, could be dose-dependent: as the clinical experiences are still limited, the optimal timing and dose of GM-CSF administration are not clearly defined. 
Therefore, we advocate further research into this topic and suggest collecting real-world clinical data about the concurrent use of G-CSF or GM-CSF and immunotherapy with ICIs, eventually uncovering their potential positive or negative influence on the outcomes of patients.

Correction notice This article has been corrected since it was first published. $\mathrm{Dr}$ Marco Merlano's affiliation has been updated to include 'FPO-IRCCS'.

Acknowledgements We apologize to authors whose work could not be cited due to space limitations, in particulars to authors of KEYNOTE-407, KEYNOTE-189, IMpower133, KEYNOTE-048, and IMpassion130 trials.

Contributors All authors contributed the manuscript concept and writing. PB, CG, $\mathrm{LL}$, and PdM made substantial contributions to conception and design and were involved in drafting the manuscript. PB, CG, LL, PdM, CS, and MM were involved in the supervision and its final revision.

Funding The authors have not declared a specific grant for this research from any funding agency in the public, commercial or not-for-profit sectors.

Competing interests $\mathrm{PB}$ has participated in advisory board or received conference honoraria from Merck, Sanofi-Regeneron, Merck Sharp \& Dohme, Sun Pharma, Angelini, Molteni, Bristol-Myers Squibb, GSK.

Patient consent for publication Not required.

Provenance and peer review Not commissioned; externally peer reviewed.

Open access This is an open access article distributed in accordance with the Creative Commons Attribution Non Commercial (CC BY-NC 4.0) license, which permits others to distribute, remix, adapt, build upon this work noncommercially, and license their derivative works on different terms, provided the original work is properly cited, appropriate credit is given, any changes made indicated, and the use is non-commercial. See http://creativecommons.org/ licenses/by-nc/4.0/.
ORCID iD

Pierluigi di Mauro http://orcid.org/0000-0002-1975-0923

\section{REFERENCES}

1 Petrelli F, Ardito R, Borgonovo K, et al. Haematological toxicities with immunotherapy in patients with cancer: a systematic review and meta-analysis. Eur J Cancer 2018;103:7-16.

2 Aliper AM, Frieden-Korovkina VP, Buzdin A, et al. A role for G-CSF and GM-CSF in nonmyeloid cancers. Cancer Med 2014;3:737-46.

3 Shojaei F, Wu X, Qu X, et al. G-CSF-initiated myeloid cell mobilization and angiogenesis mediate tumor refractoriness to anti-VEGF therapy in mouse models. Proc Natl Acad Sci U S A 2009;106:6742-7.

4 Stathopoulos GP, Armakolas A, Tranga T, et al. Granulocyte colonystimulating factor expression as a prognostic biomarker in non-small cell lung cancer. Oncol Rep 2011;25:1541-4.

5 Kumar AKL, Satyan MT, Holzbeierlein J, et al. Leukemoid reaction and autocrine growth of bladder cancer induced by paraneoplastic production of granulocyte colony-stimulating factor--a potential neoplastic marker: a case report and review of the literature. $J$ Med Case Rep 2014;8:147.

6 Bhattacharya P, Budnick I, Singh M, et al. Dual role of GM-CSF as a pro-inflammatory and a regulatory cytokine: implications for immune therapy. J Interf Cytokine Res 2015;35:585-99.

7 Hodi FS, Lee S, McDermott DF, et al. Ipilimumab plus sargramostim vs ipilimumab alone for treatment of metastatic melanoma: a randomized clinical trial. JAMA 2014;312:1744-53.

8 Parmiani G, Castelli C, Pilla L, et al. Opposite immune functions of GM-CSF administered as vaccine adjuvant in cancer patients. Ann Oncol 2007;18:226-32.

9 Tian $\mathrm{H}$, Shi $\mathrm{G}$, Wang $\mathrm{Q}$, et al. A novel cancer vaccine with the ability to simultaneously produce anti-PD-1 antibody and GM-CSF in cancer cells and enhance Th1-biased antitumor immunity. Signal Transduct Target Ther 2016;1:16025.

10 Andtbacka RHI, Kaufman HL, Collichio F, et al. Talimogene Laherparepvec improves durable response rate in patients with advanced melanoma. J Clin Oncol 2015;33:2780-8. 
Correction: Not all hematopoietic growth factors are created equal: should we gain information for their use with immunotherapy?

Bossi P, Gurizzan C, Lorini L, et al. Not all hematopoietic growth factors are created equal: should we gain information for their use with immunotherapy?. J ImmunoTher Cancer 2021;9:e003154. doi: 10.1136/jitc-2021-003154

This article has been corrected since it was first published. Dr Marco Merlano's affiliation has been updated to include 'FPO-IRCCS'.

Open access This is an open access article distributed in accordance with the Creative Commons Attribution Non Commercial (CC BY-NC 4.0) license, which permits others to distribute, remix, adapt, build upon this work non-commercially, and license their derivative works on different terms, provided the original work is properly cited, appropriate credit is given, any changes made indicated, and the use is non-commercial. See http://creativecommons.org/licenses/by-nc/4.0/.

C Author(s) (or their employer(s)) 2021. Re-use permitted under CC BY-NC. No commercial re-use. See rights and permissions. Published by BMJ.

J Immunother Cancer 2021;9:e003154corr1. doi:10.1136/jitc-2021-003154corr1

A) Check for updates 